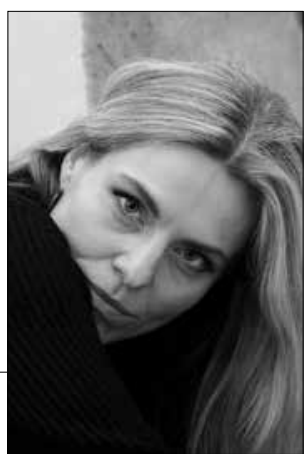

\title{
KANDINSKIS BAUHAUSE - ORIENTALISTISTINIAI IR NEKLASIKINIAI JO SPALVOS TEORIJOS ASPEKTAI
}

\author{
Kandinsky in the Bauhaus - Oriental \\ and Non-Classical Aspects of His Color Theory
}

\section{SUMMARY}

This article reveals different aspects of the color theory of Wasilly Kandinsky, which was set out in his treatise Über das Geistige in der Kunst: Insbesondere in der Malerei published in 1911. This theory - an ode to spiritual and abstract art - was inspired by non-classical philosophy, W. Worringer and the aesthetic attitudes of Eastern art. It had a strong impact on the Bauhaus design school even before the author of this theory was invited to teach at the Bauhaus in year 1922. The oriental ideas of Kandinsky significantly differed from the ideas of the Bauhaus manifesto, published by Walter Gropius in 1919. His theory encompasses the theme of color along with many other topical issues of the art. One could view this theory as an ontology-based study of the color phenomenon. The problems of art in Kandinsky's theory have been discussed beyond narrowly-understood aesthetic discourse, along with the philosophical questions of life, death, spirit and matter.

\section{SANTRAUKA}

Straipsnyje kompleksiškai analizuojama modernistinio meno korifẻjaus, vieno abstrakcionizmo pradininkų Vasilijaus Kandinskio spalvos teorija, išdėstyta jo $1911 \mathrm{~m}$. išleistame programiniame veikale Über das Geistige in der Kunst: Insbesondere in der Malerei. Ši neklasikinės filosofijos, W. Worringerio ir Rytų estetikos ỉkvėpta Kandinskio odė abstrakčiam ir dvasingam menui turejjo stiprų poveikį Bauhauso dizaino mokyklai, jos spalvos teorijai dar iki tol, kol jos autorius $1922 \mathrm{~m}$. buvo pakviestas dèstyti. Orientalistinès estetikos įkvèpto Kandinskio idejjos smarkiai skyrèsi nuo $1919 \mathrm{~m}$. Walterio Gropiuso paskelbto Bauhauso manifesto idẻjų. Jo estetinė teorija aprépia ne tik spalvą, bet ir daugybę kitų aktualių dailès ir meninès 
kūrybos procesu psichologijos problemų. Tai tarsi ontologizuota spalvos fenomeno meno filosofija, kai meno problematika svarstoma neapsiribojant siaurai suprastu estetikos diskursu, bet įtraukiami filosofiniai gyvenimo, mirties, dvasios ir materijos klausimai.

\section{SPALVOS TEORIJOS IŠTAKOS}

Dėstyti Bauhauso dizaino mokykloje Vasiliju Kandinski, P. Klee patartas, Walteris Gropiusas pasikvietè ne tik dèl jo moderniu teoriju itaigumo, bet ir tikèdamasis jo paramos kovoti dèl itakos ${ }^{1}$ su kitu Bauhauso dèstytoju, ekscentriškuoju Johannesu Itennu. Konceptualus, linkstantis i teorinius apibendrinimus ir kartu nepaprastai ramus, niekada nekeldavęs balso, elegantiškas, aristokratiškai ir įtaigiai dèstantis savo mintis Kandinskis, sugebejęs dirbti ir administracinį darbą, atrodè tinkamas ị atsakingas ",kanclerio“ pareigas šioje revoliucingų modernistinių idèju persmelktoje institucijoje, kaip kad privačioje aplinkoje ironizuodavo jo kolega Oskaras Schlemeris. Paradoksalu yra tai, kad šio išoriškai santūraus menininko pozicija, kuo neilgai trukus įsitikino ir pats mokyklos vadovas Gropiusas, priešingai lūkesčiams, pernelyg nesiskyrè nuo mazdeizmo apologeto J. Itteno ar budizmo adepto P. Klee pažiūru. Tad turëjęs tapti opozicija pastariesiems, Kandinskis entuziastingai palaike kitus du orientalistinèmis idejomis persisèmusius Bauhauso koloristus - Itteną ir Klee. Su pastaruoju ji siejo ilgametè draugystè ir panašus požiūris ì meną. Skirtumas gal tik toks, kad dẻl lankstesnio charakterio (galbūt ir dèl amžiaus, jis buvo vyriausias Bauhauso dẻstytojas, ì mokyklą ìsiliejęs 56 metu amžiaus) Kandinskiss sugebejjo išsilaikyti mokykloje iki pat jos uždarymo 1933 m., kai Ittenas pasitraukè 1923 m.,
Klee - 1931 m. Daugiau nei dešimtmeti Kandinskis Bauhause skleidè neklasikinès, rytietiškos filosofijos idejas, nuolat kalbėdamas apie, jo nuomone, visu meninių fenomenu pagrindą ,vidinę būtinybę“" (innere Notwendigkeit), ką vèliau Bauhauso tyrinètojai net vaizdingai įvardino „Kandinskio mantra“"

Visus šiuos tris ittakingu Bauhauso spalvos teoriju autorius, $\mathfrak{i}$ teorinius apmąstymus linkstančius tapytojus Kandinskị, Klee ir Itteną sieja stiprią ittaką ju pasaulèžiūrai daranti neklasikinè meno filosofija ir dèmesys Rytų kraštų filosofijai, estetikai, dailei ir poezijai. Vieno itakingiausių modernistinio meno korifejjų Kandinskio dèmesys Rytams yra visiškai suprantamas, nes diskusijose su kolegomis jis nuolatos pabrèžia savo rytietišką kilmę ir tai, kad jis, kaip rytietis, pirmiausia "mąsto vaizdiniais". Vertètu priminti, kad iš tikruju jo protèviai buvo turtingi buriatai, kilę iš Užbaikalès pagrindinio prekybos centro tarp Rusijos ir Kinijos - Kiachtos. Tikriausiai rytietiška kilmè ir buvo viena pagrindiniu priežasčiu, skatinusiu Kandinskị aistringai domètis Rytais, o tai persidavè ir daugeliui ši ekspresionizmo ir abstrakcionizmo lyderị supusiu dailininkų, pirmiausia Klee. Iš čia kyla rytietiškos estetikos natos, kurias aptinkame Bauhauso spalvos teoriju branduolyje. Jos tampa neatsiejama garsiausios XX a. dizaino mokyklos spalvos estetikos dalimi. Kandinskio 
veikalas Über das Geistige in der Kunst atitiko tuometini kultūrinio elito nusivylimą kalba, naratyvu ir tiesiogine reprezentacija vaizduojamuosiuose menuose ${ }^{3}$. Toks požiūris kilo iš pokarinės depresijos nuotaiku, taip pat buvo įkvejptas Shopenhauerio, Nietzsche's skleisto filosofinio, estetinio orientalistinio leitmotyvo, kuris, stiprejjant visuotiniam nusivylimui racionaliu, logocentristiniu binariniu mąstymu, skambèjo kaip naujos dvasinės gyvenimo kokybės pažadas.

Kandinskio spalvos teoriją kartu galime laikyti ir verbalinès, materialistinès krypties modernybès kritika, kuri, pasak autoriaus, „neturi nieko bendra su me$\mathrm{nu}^{4 \prime \prime}$ ir yra priešinga jo orientalistiniam žmogaus asmenybès suvokimui, kai išsitrina ribos tarp fizinio kūno ir psichikos ar dvasios. Kandinskiui buvo artimas Bauhauso siekis sukurti totalų meno kūrini Gesamkunstverk. Šio termino autorystė priklauso Wagneriui, kuriuo Kandinskis žavejosi (ypač vertino Lohengrina). Jam artima ir Helenos Blavatskajos teosofija - eklektiškas, ezoterinis spiritualistinis budizmas, vèliau daręs įtaką septintojo dešimtmečio New Age judejjimui. Aptariant spalvos teorijos ištakas, svarbios ir šio autoriaus draugystès su muzikais ir kompozitoriais. Pats būdamas sinestetu Kandinskis, kaip ir M. K. Čiurlionis, jautriai suvokẻ muziką. Nežinant apie jo sinestetinius gebejjimus neįmanoma suvokti jo spalvos teorijos; jo Spalvu žodynas parašytas muzikinių asociaciju pagrindu, spalvų tyrinèjimus dailininkas vadino "dvasiniais pratimais", spalvos ir formos jam buvo jausmų, emocijų, minčių išraiška, kylanti iš „vidinès būtinybès" ${ }^{\text {. }}$. Kandinskis ilgą laiką palaikè abipusiu susižavèjimu grįstus santykius su Arnoldu Schönbergu, idomus sutapimas, kad net ju abiejų knygos, padariusios didžiulę i̇taką XX a. meno, estetikos suvokimui, išejo tais pačiais metais: $1911 \mathrm{~m}$. Schönbergas išleido Harmonielehre (Theory of Harmony), Kandinskis - Über das Geistige in der Kunst (Concerning the Spiritual in Art). Schönbergas buvo ne tik kompozitorius, bet ir dailininkas, jo dvylikos muzikiniu tonų schema pagal chromatinę skalę atitinka tuometini Bauhauso požiūrị, kad bet koki principa galima pavaizduoti shemomis bei diagramomis ${ }^{6}$ atsisakant tiesioginès reprezentacijos. Abu menininkus siejo ir panašūs kūrybiniai tikslai. I 1911 m. Kandinskio parašytą laišką (kartu su pridètu paveikslu portfolio), kuris tapo ilgametės draugyste pradžia ir kuriame dailininkas rašo, esą Schönbergui muzikoje pavyko ikūnyti tai, ko jis taip ilgejęsis, Schönbergas atsake esantis tikras, kad ju darbas turi daug bendra: „ką jūs vadinate „nelogišku“, aš vadinu sąmoningos valios atsisakymu mene ${ }^{\prime 7}$. Juos siejo autentiškos raiškos šaltinio paieškos, igimtų, instinktyviu dalykų sureikšminimas.

Kandinskiui idejiš̌kai ypač artimas mūsų talentingiausias dailininkas ir kompozitorius Mikalojus Konstantinas Čiurlionis, daug ginčijamasi dèl ju prioriteto abstraktaus meno genezeje $e^{8}$. Čiurlioni, kaip ir Kandinskị, stipriai veikè XIX a. pabaigos - XX a. pradžios orientalistinès tendencijos, nyčiškoji gyvenimo filosofija, jo kūryboje (ir gyvenime) prioritetas teiktas dvasiniam pradui, o materialinès vertybès visai nesvarbios. „Dešimt metu anksčiau nei A. Schönber- 
gas jis kūrè serijines kompozicijas, atviras neišbaigtas muzikines formas. Non finito principas Čiurlioniui buvo ne manieringumo ar arogancijos pasireiškimas o, kaip ir jo brandžioje, Tolimuju Rytu estetikos îkvèptoje tapyboje, natūrali žmogiškosios asmenybès principinio neišsakomumo pasekmè ${ }^{9 " . ~ C ̌ i u r l i o n i o, ~ k u-~}$ ris pirmuosius abstrakčius paveikslus nutapé 1906-1907 m. (t. y. tik metais vèliau nei Adolfas Hölzelis, 1905 m. nutapes Komposition in Rot, neretai pirmaja abstrakcija laikoma kūrini), kūryba neabejotinai turèjo ịtakos Kandinskiui. Akademiko A. Sidorovo, kuris daug metu artimai bendravo su V. Kandinskiu, teigimu, šis ne kartą kalbèjo norįs „,nugalèti Čiurlioniّ“10. Tikètina, jog būtent Kandinskio iniciatyva M. K. Čiurlioniui (tuo metu jau sunkiai sergančiam) buvo išsiųstas kvietimas dalyvauti programinèje naujos modernistinio meno grupuotès Neue Künstlervereinigung München (,NNaujosios Miuncheno dailininkų sajungos“) parodoje. Deja, šioje parodoje dèl sveikatos problemų Čiurlionis nedalyvavo.

Kandinskị ir Čiurlionį (taip pat Schönberga, Klee) siejo ir sinestetinės patirtys labai svarbus (gal net lemiamas) veiksnys kalbant apie Kandinskio spalvos teorijos ištakas. Turbūt tuo, jog Kandinskis negalejo racionaliai suvokti ir izvardinti kylančių pojūčių, kuriais grindè savo spalvos teorija, galima paaiškinti jo, viena vertus, kategoriškumą ir i̇sitikinimą savo tiesa, kita vertus, paradoksalią abejonę savo teorijomis. Kandinskiui kylančią tipišką polemiką galima pailiustruoti šiuo komentaru, išsakytu psichologui P. Plautui: „man šiandien patinka apskritimas, kaip kad anksčiau, pavyzdžiui, patiko ar- klys, - turbūt net labiau, kadangi randu daugiau vidinès potencijos apskritime, jis užèmè arklio vietą [...], savo paveiksluose aš pasakiau daug didžių "naujų" dalykų apie apskritima, bet teoriškai, nors ir dažnai bandžiau, negaliu labai daug pasakyti“11. Kandinskio "tikrumas" savo tiesa, neretai akcentuojamas jo biografų, veikiausiai reiškia menininko užtikrintumą savo kūryba, kuri nebūtinai turi pažodiškai sutapti su teorija, ši (kaip kad spalvos teorijos atveju) yra tik tam tikros gairès ar modelis - veikianti, tačiau ne absoliuti schema.

Kandinskio spalvos teorijai ittaką darè ne tik meninè, kultūrinè terpè, kurioje jis sukosi, tačiau ir artimesnè - namų aplinka: visu pirma tos sąlygos, kuriomis jis užaugo, vèliau ir šeimyninis gyvenimas. Jo senelè iš tèvo pusès buvo buriatè, su ja sieja rytietiškos pasaulèžiūros organiškumas ir natūralumas Kandinskio kūryboje. Idomu tai, kad senelè iš motinos pusès buvo kilusi iš Pabaltijo kraštų, galbūt todèl Kandinskis ne kartą lankèsi šiuose kraštuose, domėjosi vietos dailininkų kūryba, i jo akirati pakliuvo M. K. Čiurlionio tapyba. Kandinskio tèvas, turtingas arbatos pirklys, dailininko žodžiais tariant, "humaniška ir mylinti siela"12, tikèjosi, kad sūnus susies savo likimą su menu, tad samdè jam privatu piešimo mokytoja o dešimties metų leido apsispręsti, kokią mokyklą rinktis mokslinès krypties ar humanitarinès. Sūnui pasirinkus humanitarinès krypties studijas, buvo nepaprastai patenkintas.

Nors Kandinskio aplinka buvo jam palanki ir jis galejo atsidèti tik menams, vis dèlto devyniolikos metu jis imasi teisès ir ekonomikos studijų, manydamas, 
kad menas yra per didele „ekstravagancija"13 rusui. Tapybos niekada nemetè, jai tuo metu skirdavo visą laisvą laiką, o vèliau ji tapo didžiausiu prioritetu. Atrodo, kad stiprus kūrybinis polinkis bei spalvinè „klausa“ Kandinskiui buvo igimta, jis tekstuose mini savo pirmąsias sinestetines patirtis, tik treju metų amžiaus, kai ankstyvieji estetiniai, neipprastai ryškūs spalviniai pojūčiai sukelia baimę, nerimą ir kartu susižavejjimą bei trauką prie keistų spalvų pasaulio, kuriame išsitrina riba tarp regos, uoslès, garso ir net skonio, - kasdienè aplinka patiriama lyg vientisas estetinis universumas. Jo spalvu teorijai šios patirtys buvo nepaprastai svarbios, leidusios tuometines koloristikos studijas pakylèti i naują lygmeni, suteikti naujų, netikètú spalviniu kokybių. Baimè, jaudulys ir susižavejimas, artimas ekstazei, ir vèliau neretai „ištikdavo“ ji vienu metu. Pasibjaurèjimas kuria nors spalva ar veikiau sinestetine asociacija, kurią ši sukeldavo, galèdavo tuo pat metu turèti ir koki nors pozityvų aspektą.

Ypatingas yra Kandinskio santykis su juoda spalva, nuo paauglystès kèlusia neigiamas asociacijas, kurias dailininkas panaudojo savo baimių izveikai. Pavyzdžiui, nepaisant to, kad ir „vèliau juodos tepimo ant drobės perspektyva keldavo Dievo baimę ${ }^{\prime 14}$, savo name Dessau (kuriuo dalinosi su Klee šeima) valgomojo sieną nudažè gryna juoda spalva. Šią spalvą taip pat galime pastebèti beveik visuose jo paveiksluose, o jos naudojimo metodai artimi Rytų kraštų, japonų spontaniškosios tapybos, kinų kaligrafijos principams. Tam tikras blaškymasis, svyravimas tarp racionalių disciplinų ir meno, susipinančios dvilypès, pozityvios ir negatyvios estetinès patirtys, mèginimas visa tai reflektuoti ivvairiais būdais pasitelkiant teksta, vaizduojamuosius menus, muzika, nereiškia, jog Kandinskis, kaip menininkas ar teoretikas, abejoja, tačiau iliustruoja ypatingą jo asmenybès jautruma, dèl kurio santykis su empiriška, kasdiene tikrove tampa, viena vertus, komplikuotas, sudètingas, kita vertus, autentiškas ir universalus.

Galbūt savo psichikos jautrumą jis paveldèjo iš nervingos motinos, tačiau taip pat tikètina, kad subtiliausių kasdienybės niuansų daugiaspalvis patyrimas ir pabrèžtino jautrumo ju refleksija kyla iš visiems sinestetams būdingu ypatingu juslinių sugebèjimų. Ittakingas vokiečių modernistinio meno istorikas W. Grohmanas mano, kad savotiškas Kandinskio atsitolinimas, distancija, kurią šis visuomet išlaikydavo bendraudamas, yra slèpimas tam tikro vidinio nestabilumo, kurị dailininkas mėgino maskuoti pabrèžtina savikontrole bei vadinamosiomis „pusiau draugystėmis ${ }^{15 “, ~ n i e k o ~ n e-~}$ isileisdamas pernelyg arti. Jame derèjo, atrodytu, nesuderinamos savybès: laisvumas, patosas, misticizmas ir kartu dogmatiškumas bei šaltumas, unikalią charizmą kūrè paradoksalūs bruožai.

Turbūt nesuklysime apibūdinę ši ypatingo talento modernistinio meno korifëją kaip aistringa, novatorišką laisvamani su santūraus, net konservatyvaus džentelmeno kauke. Toks charakterio daugialypumas lèmè ir skirtingus Kandinskio vertinimus bei jo kūriniu traktuotes. Gausioje kritinejje literatūroje jis vertinamas ne tik kaip abstrakčiosios dailès pradininkas, genijus, bet ir aukšto lygio teoretikas, vienas ittakingiausių mo- 
dernistinio meno Bauhauso idejinis lyderis, kurio asmeniniai tikslai (kaip ir kitų dvieju Bauhauso spalvos teoriju korifëjų) nesutapo su pragmatiškais, programiniais mokyklos tikslais: estetiką pajungti materialiems, perdèm žemiškiems poreikiams, tarsi „nušauti du zuikius" kuriant i masinę gamybą orientuotus objektus, kurie turètų ir meninę vertę. Tačiau Kandinskis daugeli savo mokinių ir sekèju pastūmèjo ì priešingą pusę, skatino juos gilintis iz ivairius mįslingus, sunkiai suvokiamus psichologinius ir net psichopatologinius reiškinius, neretai artimus neurotinèms būsenoms. Nors pats giliai išgyveno vidines abejones, absoliučiai tikejjo naujo gyvenimo aušra, kai dvasia „pajudins kalnus“, ir tapyba, iškeldama tai, kas geriausia žmoguje, nugalès vulgaru materializmą ${ }^{16}$. Šio ambicingo uždavinio pagrindiniu įrankiu Kandinskis pasirinko jam kaip si-

\section{Literatūra ir nuorodos}

${ }^{1}$ Nicolas Fox Weber, The Bauhaus Group / Six Masters of Modernism. New Haven, London: Yale University Press, 2011, p. 220.

2 Hal Foster citata iš: Bary Bergdoll; Leah Dickerman, Bauhaus 1919-1933: workshops for modernity. New York: The Museum of Modern Art, 2009, p. 266.

${ }^{3}$ Bary Bergdoll, ten pat, p. 23.

${ }^{4}$ Kandinsky citata iš: Bary Bergdoll; Leah Dickerman, Bauhaus 1919-1933: workshops for modernity, p. 24.

${ }^{5}$ Lenina. N. Mironova, Uchenie o cvete, Minsk: „Visheishaja shkola“, 1993, p. 343.

6 Bary Bergdoll; Leah Dickerman, Bauhaus 19191933: workshops for modernity, p. 24.

7 Schönbergo citata iš: Nicolas Fox Weber, The Bauhaus Group / Six Masters of Modernism, p. 227. nestetui dvasiškai artimiausius meninius fenomenus, visų pirma psichologiškai interpretuojamas ivvairias vidines meninio kūrybos proceso būsenas, kurios šiam sinestetui pirmiausia asocijavosi su spalvos fenomenu. „Vidinè būtinybè, teigia jis, - yra svarbiausia tarp mažu ir didelių problemų mene. Šiandien mes ieškome kelio, kuris nuves mus tolyn nuo išoriškumo (materialumo) prie vidujybès pagrindo. Dvasia, kaip ir kūnas, turi būti stiprinami ir lavinami nuolatinių treniruočių. Kaip kad kūnas, jei apleidžiamas, ima silpnèti ir galiausiai tampa bejègiu, taip dvasia žūva, jei apleidžiama. Pradžios taškas yra spalvos ir jos poveikio žmogui studijavimas. "17

Norèčiau atkreipti skaitytojų dèmesi, kad vidinę būtinybę jis sugebejjo fenomenologiškai ižziūrèti beveik kiekviename kasdienybès objekte, kurio patyrimas tapdavo aukščiausiu estetiniu aktu.

\footnotetext{
8 Antanas Andrijauskas, Kultūros, filosofijos ir meno profiliai (Rytai-Vakarai-Lietuva). Vilnius: KFMI 1-kla, 2004.

9 Ten pat.

10 Ten pat.

11 Kandinskio citata iš: Nicolas Fox Weber, The Bauhaus Group / Six Masters of Modernism, p. 234.

12 Kandinskio citata iš ten pat, p. 208.

13 Kandinskio citata iš ten pat, p. 208.

14 Kandinskio citata iš ten pat, p. 208.

15 Kandinskio citata iš ten pat, p. 206.

16 Ten pat, p. 215.

17 Wassily Kandinsky, Concerning the spiritual in art. New York: Dover Publications, Inc, 1977, p. 35-36.
}

B. d. 